\title{
Scanning Densitometer for Continuous Recording of Spectral Transmission Density at Low Spatial Contrast*
}

\author{
W. L. McLaughlin, M. Rosenstein, ${ }^{1}$ E. K. Hussman, and J. J. Lantz, Jr. \\ Center for Radiation Research, National Bureau of Standards, Washington, D.C. 20234
}

(October 6, 1970)

\begin{abstract}
A simple photoelectric transmission densitometer can be converted in the laboratory into an instrument for measuring spatial variations in spectral density of small areas of thin, nonturbid films. This is accomplished by adding relatively inexpensive components that are readily available and easily assembled. The basic instrument can be one of a number of commercial densitometers, consisting of stabilized electronics, an adjustable light source, and a photosensitive probe which has a wide range and measures spectral transmission density. For continuous scanning of relatively small sample areas, the followng additions are needed: (1) narrow-bandpass filters; (2) interchangeable field illuminating slits; (3) a short-focal-length illuminating-condenser lens which compromises between a relatively large numerical aperture and a reasonable depth of focus; (4) a motor-driven stage with adjustable speeds; (5) a light diffuser and light guide; and (6) a continuous, relatively fast-response data-recording system (such as a fast-response strip-chart recorder). This instrument has been assembled and tested especially for measuring spatial variations of spectral density produced in irradiated photochromic films; and also for calibrating a train of irradiated film samples, in terms of transmission density at a given wavelength as a function of irradiance, radiation absorbed dose, or photochemical reactivity.
\end{abstract}

Key words: Densitometer; microdensitometer; radiochromic dye films; spectral transmission density.

\section{Introduction}

With the increasing use of thin gel, polymer, and photochromic films in chromatography and ionizing radiation applications, such as obtaining beam profiles, registering chemical-reactivity, depth-dose, or penetration distributions, monitoring high-intensity radiation fields, and monitoring beam uniformity in radiation processing of industrial products, there is a need for continuous optical-density scanning at given wavelengths across relatively small areas of these films. A commercial microdensitometer is suitable for very high resolution work, such as determining granularity of images, modulation transfer functions of imaging systems, or acutance of photographic images [1-4], ${ }^{2}$ but is expensive and difficult to use for large volumes of routine work. The aim of the present work is to show how a simple, inexpensive photometric apparatus can be assembled and used to measure spectral transmission densities [5] of relatively nonscattering thin-film images with moderate spatial resolution.

Most microdensitometers have two objective lens-slit systems: an illuminating and a scanning system. The illuminating system is situated between the light source and the sample. The scanning objective lens focuses a certain area of the narrow sample image on a reading slit in front of the photocathode. These components are

* This work was partly supported by the Division of Isotopes Development, U.S. AEC.

1 Bureau of Radiological Health, Environmental Health Service, Rockville, Md. and Graduate Student, Laboratory for Radiation and Polymer Science, University of Maryland, College Park, Md. Guest worker at the National Bureau of Standards.

2 Figures in brackets indicate the literature references at the end of this paper.
Stand arranged so as to reduce errors due to flare from the sample, diffraction from the apertures caused by partial coherence in the illumination, and film granularity $[6,7]$. Great pains have to be taken to improve performance by adjusting the components so as to minimize angular and focal misalinements and non-uniform photocathode sensitivities [8]. The slit images falling on the photosensor are narrow in order to reduce adjacency effects [9].

The instrument described here is not a conventional microdensitometer, in that a scanning lens-aperture system has not been used; rather the slit-image of narrowband light focused on a small area of the relatively nonscattering photochromic film is transmitted according to the spectral density of that area, and then is diffused and channeled efficiently to the photomultiplier. A schematic chart displaying the main components is shown in figure 1. Relatively turbid samples, such as developed silver halide emulsions, would cause excessive light-scattering in such an arrangement, so that a scanning objective lens would be needed to focus the small portion of sample image through a scanning slit on the photocathode. The instrument diagrammed in figure 1 should be restricted to use with relatively nonturbid, nonreticulated plastic films, photochromic layers, and chromatographic gels. The light passes through a multiple filter system to a slit whose image is reduced and focused on the sample. Essentially all the light transmitted by the sample is first diffused and then collected by the photomultiplier. The photomultiplier current (proportional to spectral density) can be read relative to the lateral film position by an electrometer, an electrometer connected to a strip-chart 


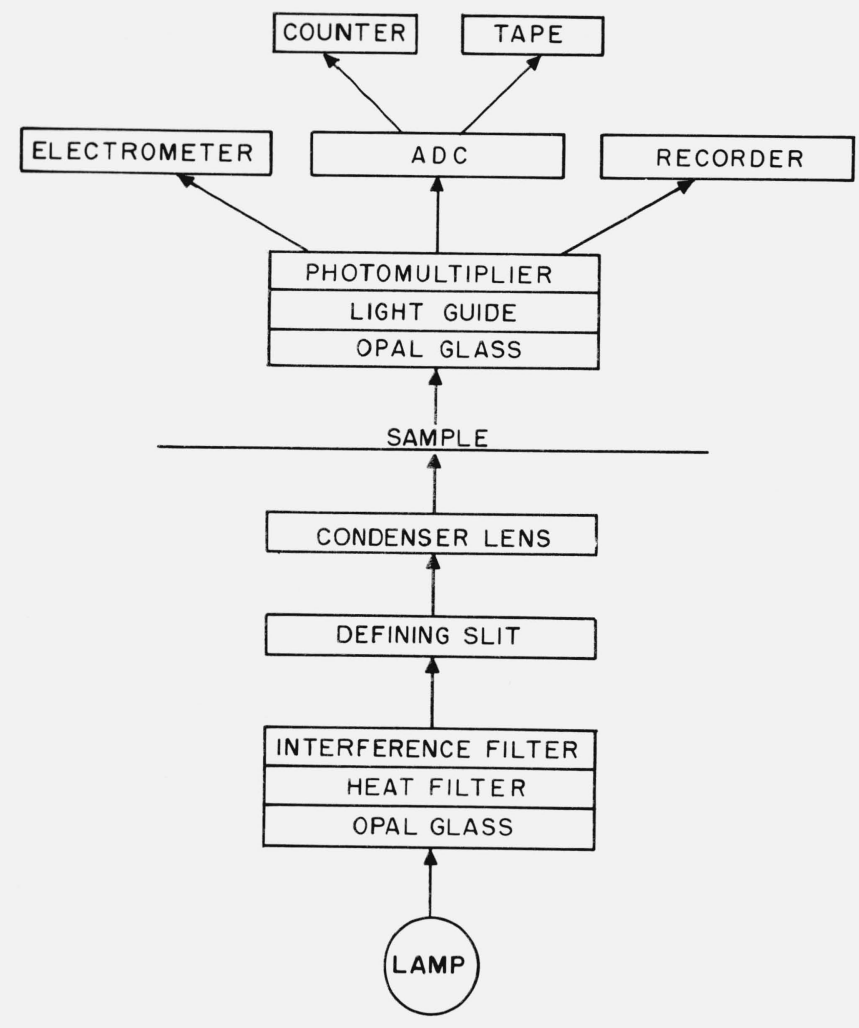

Figure 1. Schematic chart of main components of densitometer scanning slit and light collection system.

recorder, or, in an expanded system, an analog-to-digital converter may be used and the resulting pulses fed into a tape-recorder readout. The light-collecting system is similar to microscope systems used in recording histophotometers for integral density scanning of small biological specimens or for microscopic spectrophotometry, in that essentially all transmitted light from a small sample area is collected and measured [10-12]. A removable thin focusing screen can be placed into the plane of the sample for sharp focusing of the slit image while viewing with an 8-power lens.

The main limitation of the nonfocusing diffuse-light gathering system is that only moderate spatial resolution is possible, even with relatively nonscattering media. The main advantages are that problems of diffraction, critical slit alinement, focal adjustment, and nonuniformity of photocathode sensitivity are less severe than for a microdensitometer. Even though granularity noise in turbid materials, such as developed silver halide emulsions, would be averaged somewhat by the present system, the scattering of light by the same would result in flare and limited definition of the measured image.

\section{Instrumental Details}

The basic instrument, adapted for the purposes described here, can be one of a number of photoelectric densitometers with a wide response range, adjustable lamp brightness, and stabilized electronics. ${ }^{3}$ The adaptation for continuous recording of spectral densities of small areas can be accomplished at relatively low cost without disturbing the primary function or operation of the original instrument. If necessary, the instrument can easily be returned to its original configuration to measure macroscopic diffuse optical densities of large specimens.

Figures 2 and 3 are photographs of details of the added components. Figure 2 shows the drive, gear, and counter combination which is powered by a variable d-c power supply. Inexpensive permanent-magnet reversible-type motors with integral reduction gearing drive the wormgear screwjack. Limit switches are mounted to the body of the jack to prevent over-travel. At full voltage, the film

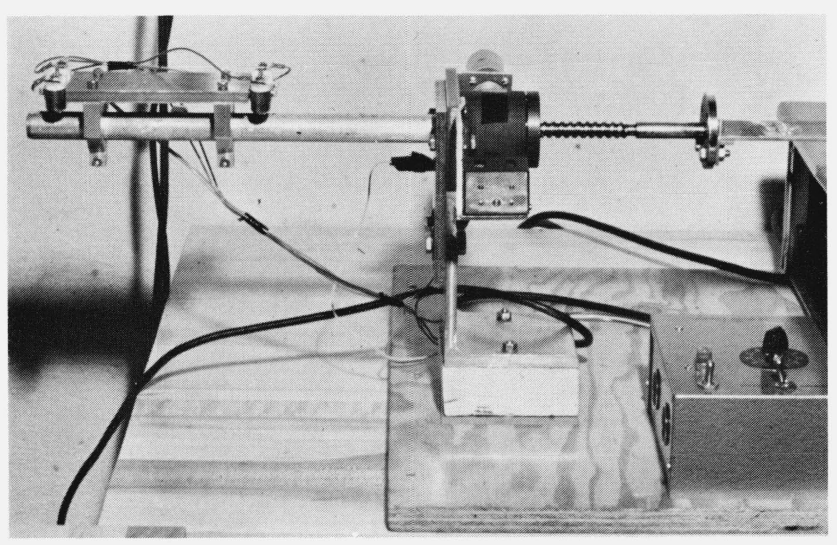

Figure 2. Close-up photograph of drive, gear and counter assembly and d-c power supply.

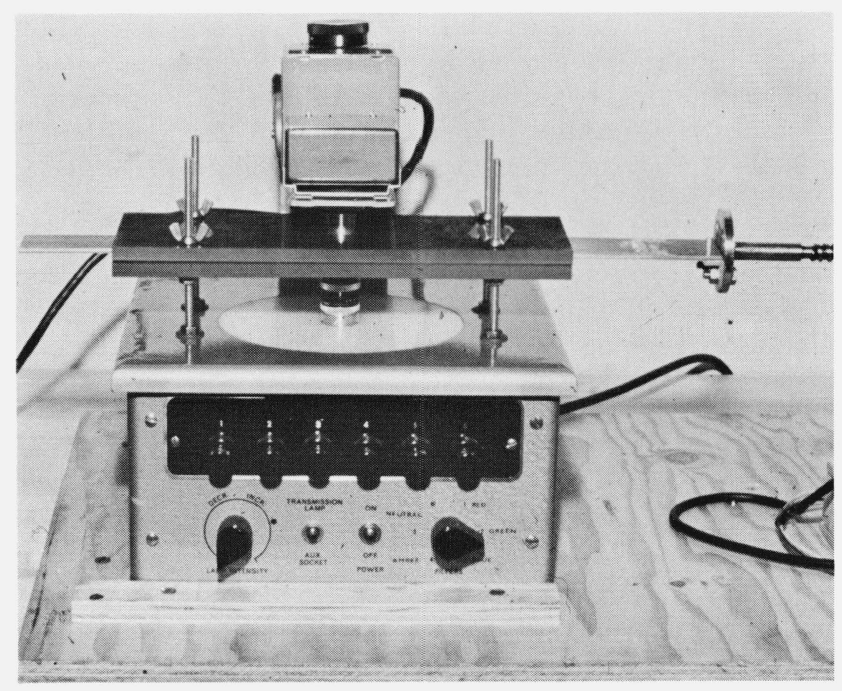

Figure 3. Close-up photograph of scanning densitometer as arranged during operation.

3 For example, the apparatus used in this application was a Welsh Densichron Model 400 Phetometer and Densichron 3853D Transmission light source. (Thi equipment is identified here in order to specify the instrumental details ade quately. Such identification does not imply recommendation nor endorsement by the National Bureau of Standards.) 
holder directly connected to the jack moves laterally in either direction across the photometric aperture at 2 $\mathrm{mm} / \mathrm{s}$. Slower speeds variable down to $8 \mu \mathrm{m} / \mathrm{s}$ are possible by lowering the voltage with a rheostat and by using reduction gears. In order to monitor the relative sample position, a calibrated revolution counter is used. These parts provide satisfactory reproducibility and control of the position of samples, without requiring more expensive synchronous motors or stepper motors and gear trains.

Figure 3 shows the scanning densitometer in its operating mode. The sample holder is continuously movable from left to right or vice versa in a horizontal plane across the slit. A vernier scale allows positioning of the sample perpendicular to the scanning direction. The vertical position of this whole assembly is also adjustable for use with different illumination lenses which focus the illumination slit images in a given horizontal plane. The sample holder has a variable opening and can hold films or plates as large as $20 \mathrm{~cm}$ long by $3.8 \mathrm{~cm}$ wide.

For the purpose of carrying out many simple spatial density gradient readings, an inexpensive drive-strip chart recorder system is satisfactory. If a more sophisticated readout is required, particularly in the case of largevolume data acquisition, an analog-to-digital converter can be used. In the latter case, a ramp voltage can be supplied via a servo loop to drive the motor in stages and thus give a record of optical density as a function of position.

Since one of the main purposes of the instrument is to make spectral-density measurements at optical wavelengths near the absorption maxima of particular photochromic and plastic films, special consideration has been given to providing intense essentially monochromatic light sources corresponding to the wavelengths of the absorption peaks of interest. Interference filters which have been used successfully in spectrophotometry [13] were fitted to the instrument for this purpose. In this case, the optical density measured is standard spectral density $[5,14,15]$. Table 1 lists the filters used, according to wavelength passed, their characteristics in terms of maximum percent transmittance, and spectral bandpass full width at half maximum. Also listed are the plastic or dye films for which the change in absorption characteristics due to irradiation is most pronounced at the indicated wavelength.

TABLE 1. Interference filter characteristics and corresponding radiochromic film type measured at a particular wavelength

\begin{tabular}{|c|c|c|c|}
\hline $\begin{array}{l}\text { Transmittance } \\
\text { wavelength } \\
(\mathrm{nm})\end{array}$ & $\begin{array}{l}\text { Maximum } \\
\text { percent } \\
\text { transmittance }\end{array}$ & $\begin{array}{l}\text { Band width } \\
\text { at half max. } \\
\quad(\mathrm{nm})\end{array}$ & $\begin{array}{l}\text { Radiochromic } \\
\text { film type }\end{array}$ \\
\hline 401 & 44.7 & 10 & polyvinylchloride \\
\hline 436 & 55.5 & 10 & $\begin{array}{l}\text { methyl yellow } \\
\text { malachite green }\end{array}$ \\
\hline 559 & 59.4 & 10 & $\begin{array}{l}\text { pararosaniline } \\
\text { new fuchsin }\end{array}$ \\
\hline 601 & 58.5 & 10 & $\begin{array}{l}\text { hexahydroxyethyl violet } \\
\text { crystal violet }\end{array}$ \\
\hline 620 & 60.0 & 10 & malachite green \\
\hline 640 & 80.0 & 10 & $\begin{array}{l}\text { blue cellophane } \\
\text { red Perspex }\end{array}$ \\
\hline
\end{tabular}

Several interchangeable slits have been made by an electrical-discharge machining process [16] in aluminum and blackened to reduce reflection from the edges. A list of these slits and their effective image size at the sample plane, when a 4-power, 3.0 numerical aperture condenser lens is used as an illumination condenser system, is given in table 2 .

TABLE 2. Effective image sizes of slits used with scanning densitometer

\begin{tabular}{cc}
\hline $\begin{array}{c}\text { Illuminating slit } \\
\text { (width } \times \text { height, mm) }\end{array}$ & $\begin{array}{c}\text { Effective image } \\
\text { (width } \times \text { height, mm) }\end{array}$ \\
\hline $0.068 \times 7.0$ & $0.018 \times 1.84$ \\
$.133 \times 1.0$ & $.035 \times 0.26$ \\
$.25 \times 2.0$ & $.066 \times 0.53$ \\
$.50 \times 3.0$ & $.13 \times 0.79$ \\
$1.0 \times 7.5$ & $.26 \times 1.97$ \\
\hline
\end{tabular}

The lens is an achromatic, spherical-aberration-corrected short focal-length $(5.5 \mathrm{~mm})$ lens with an aperture variable from $f / 1.8$ to $f / 22$. The lens is positioned at a distance from the slit somewhat greater than twice the focal length and the distance between the lens and sample falls between one and two focal lengths. In this geometry, the dimensions of the slit image focused on the sample are between one-third and one-fourth of the slit dimensions. It should be observed from the combination of the smallest effective slit width $(18 \mu \mathrm{m})$ and the numerical aperture of the lens at full aperture that diffraction at the wavelengths of interest is not a handicap. A slit of this size is still large enough to produce adjacency effects when used for viewing samples with high spatial frequency; however, in most images encountered in the present work, with the exception of edge images, only relatively small variations in optical density occur over a distance the size of the slit width.

\section{Instrument Performance}

It was noted earlier that the scanning densitometer is not suitable for evaluation of turbid photographic films with high spatial contrast due to excessive light-scattering effects. An example of this limitation is demonstrated in figure 4, where a knife-edge image made on photographic film is shown: (1) as traced by a commercial microdensitometer, and (2) superimposed, as traced by the scanning densitometer. Due to the procedure for calibrating the instrument, data from the scanning densitometer were originally obtained in terms of transmittance. For purposes of comparison with data in figures 4 and 5 from the microdensitometer, these data have been converted to optical density, where

$$
\text { Optical Density }=-\log \text { (Transmittance). }
$$

Both traces were made with $601 \pm 10 \mathrm{~nm}$ (full width at half maximum) light provided by an interference filter; the effective slit of the microdensitometer was $16 \mu \mathrm{m} \times$ $800 \mu \mathrm{m}$ and the effective slit image of the scanning densitometer was $18 \mu \mathrm{m} \times 1,840 \mu \mathrm{m}$. An objective measure of sharpness for sigmoid-shaped traces is acutance, which is calculated from the relationship [17]: 


$$
\text { Acutance }=\frac{\sum_{i=1}^{n}(\Delta D / \Delta x)_{i}^{2}}{n\left(D_{\mathrm{B}}-D_{\mathrm{A}}\right)}
$$

where,

$(\Delta D / \Delta x) i=$ density change per corresponding trace distance (microns) for each of $n$ equally spaced trace distances between $D_{A}$ and $D_{B}$.

$D_{A}, D_{B}=$ optical density at points on knife-edge trace where $\Delta D / \Delta x$ is $0.005 \mu \mathrm{m}^{-1}$.

Acutance for the microdensitometric trace of the photographic knife edge, using $n=10$, was a factor of about 10 higher than for the scanning densitometer. In addition to loss of resolution in the trace of the scanning densitometer, a second degradation of the knife-edge trace is observed due to flare from the illumination of the knife edge. Flare [7, 17] arises from light reflected into the emulsion when a bright region surrounds the image and is within the field of the detector. This is the case when a photographic knife edge is viewed by the scanning densitometer. The result is a reduction in optical density due to collection of extraneous light in the detector. Flare is primarily a function of the material being viewed; it is not a serious problem with the nonturbid films for which the scanning densitometer was designed.

Calculations have been reported of modulation transfer functions (MTF's) for microdensitometer systems from knife-edge traces based on Fourier-transform techniques and convolution methods [17-19]. These computational techniques, with the aid of high-speed computers, can generate separate MTF's for the photographic system and the microdensitometer from knife-edge scans and provide other basic information required for the evaluation of image quality. Such an elaborate analysis was not deemed appropriate for the scanning densitometer because the instrument is not proposed for high-resolution work, but rather as a mechanical apparatus for the purpose of driving a scanning slit across a nonturbid film having relatively low spatial contrast.

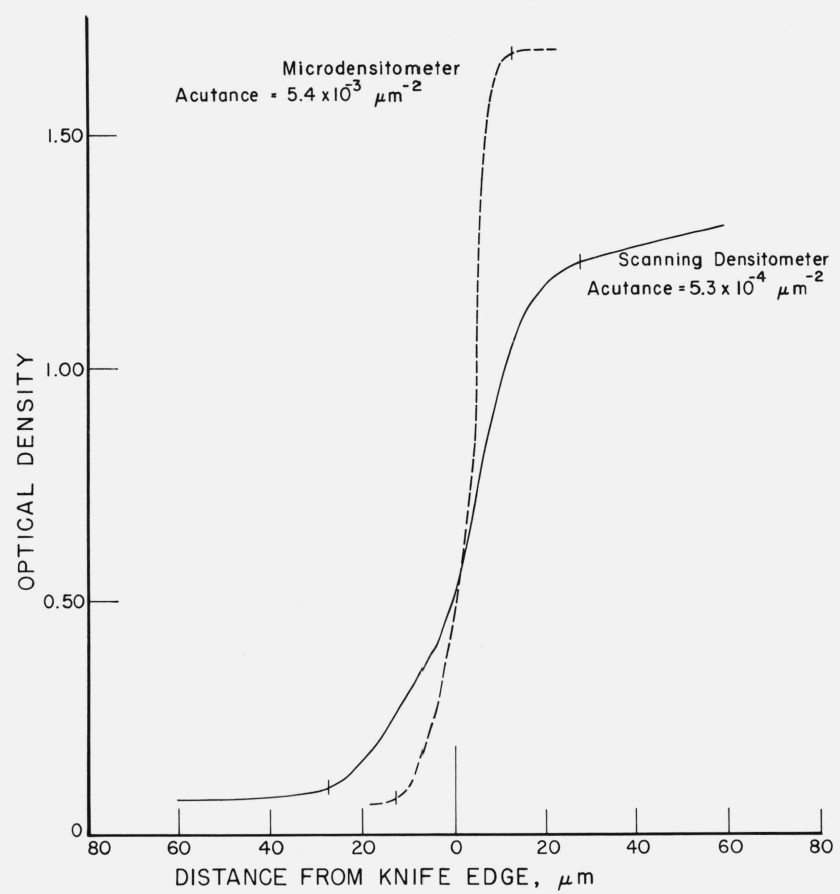

Figure 4. Comparison of photographic knife edge traces for commercial microdensitometer (dotted line) and scanning densitometer (solid line).

Vertical marks on the traces indicate the points between which acutance was determined $\left(\Delta D / \Delta x=0.005 \mu \mathrm{m}^{-1}\right)$.

The most practical measure of the performance of the scanning densitometer is by comparison of optical density traces of nonturbid films with traces produced by a commercial microdensitometer. A typical comparison is shown in figure 5, where traces of an exposed radiochromic dye film, which has recorded the spatial-distribution of dose (proportional to optical density) with depth in a medium, are drawn on the same scale. The important feature of the comparison is the overall agreement in the optical-

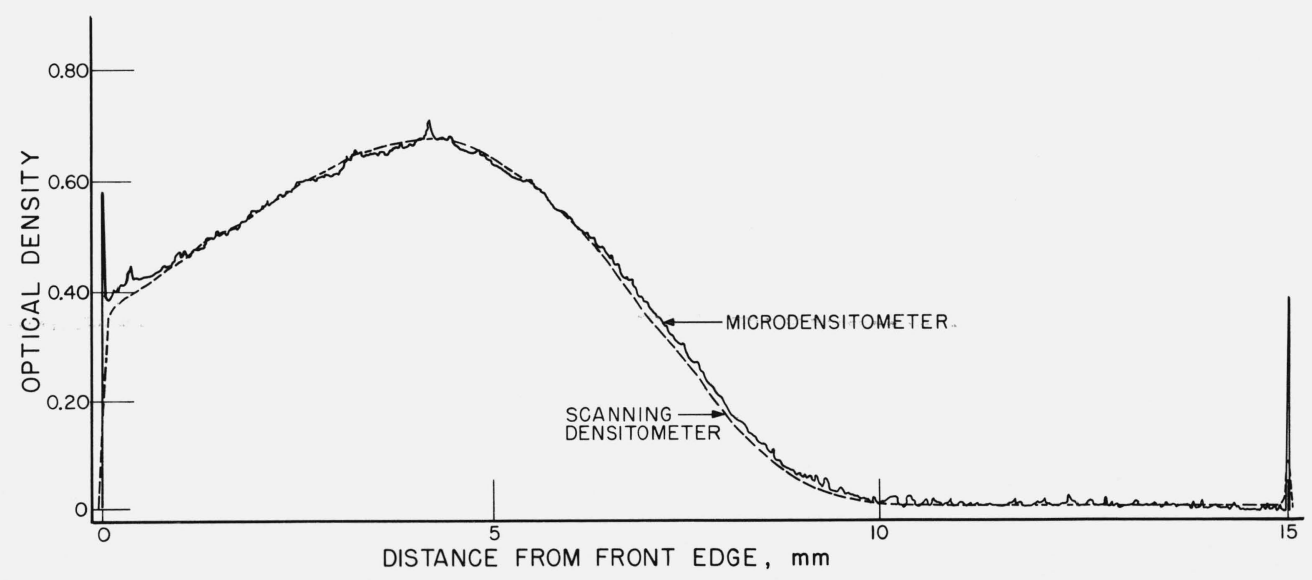

FIGURE 5. Comparison between spatial optical density tracings of an irradiated radiochromic-dye film for commercial microdensitometer and scanning densitometer. 


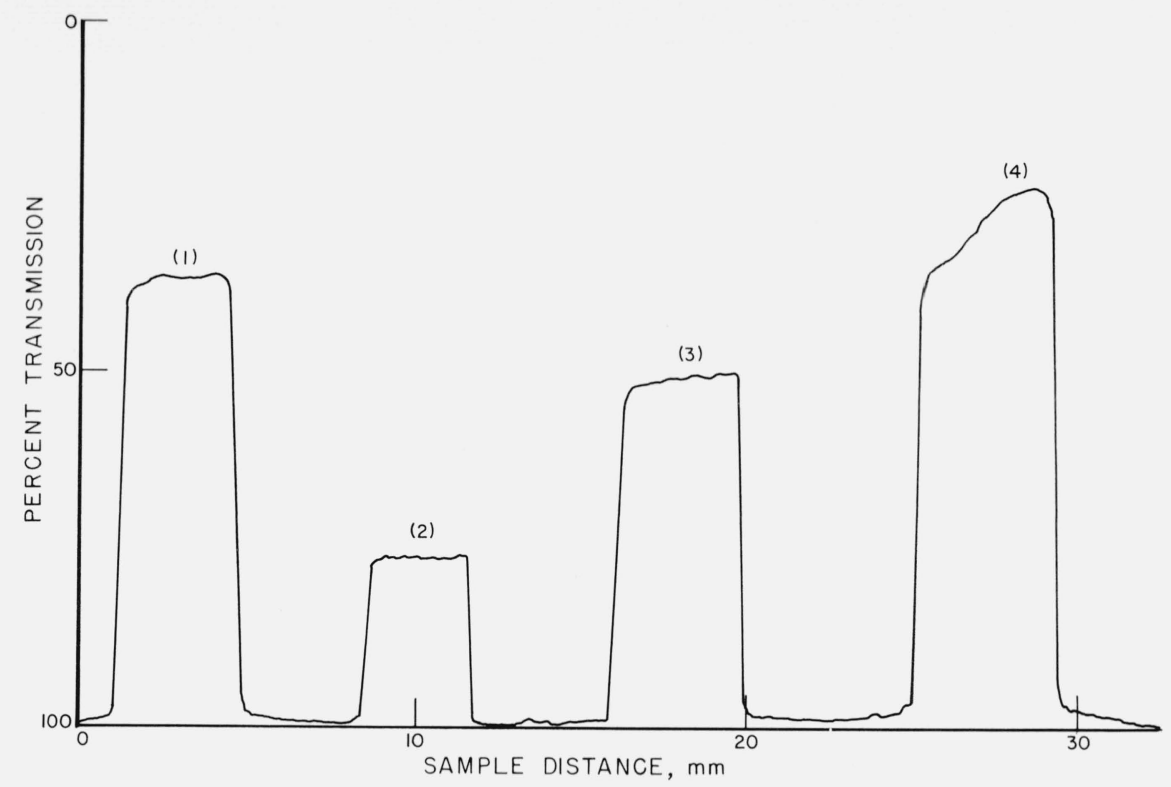

Figure 6. Scanning densitometer trace of a series of irradiated radiochromic dye films.

(1), (2), and (3) are calibration films exposed to a uniform radiation field, and (4) is the depth-dose response of a film inserted longitudinally in a $4 \mathrm{~mm}$ thick phantom. The steep vertical lines represent the edges of the individual films.

density trend between the two traces. As expected, the film edge is more clearly defined in the commercial microdensitometer trace. The sharp spikes evidenced there are responses to small scratches and dust particles which cannot be resolved by the scanning densitometer. It is also observed that the problem of flare noticed with the photographic knife edge is not as pronounced at the edges in the traces of these radiochromic dye films. Except for the improvement in determining the position of the edge of the film, no great advantage would be gained in using the more sophisticated microdensitometer, since the instrument resolution required to register gradual spatial variations in the dye films is available from the scanning densitometer. As an example of a practical application of this instrument, figure 6 shows a trace of a series of irradiated radiochromic-dye films read in tandem on the densitometer.

\section{Summary}

A simple, inexpensive, scanning densitometer, with effective viewing areas as small as $(0.035 \times 0.26) \mathrm{mm}^{2}$ or $(0.018 \times 1.84) \mathrm{mm}^{2}$, has been designed and assembled. It is based on existing components, namely a commercial photoelectric densitometer, an illuminating optical-slit system with various wavelengths of monochromatic light, a variable-speed sample driving mechanism and table, and a continuous fast-response readout system. Experiments have shown that images of relatively low spatial contrast on thin nonturbid photochromic films can be scanned competitively with more expensive and complicated microdensitometers. Advantages are that alinement, diffraction, focal adjustment, and photocathode non-uniformity are not severe problems with the instrument described. Disadvantages are that high spatial frequency and sharp knife-edge images on turbid media cannot be handled adequately with this system.

\section{References}

[1] Altman, J. H., and Stultz, K. F., Rev. Sci. Instr. 27, 1033 (1956)

[2] Southwold, N. K., and Waters, W. G., J. Photo. Sci. 7, 174 (1959)

[3] Miller, C. S., Parsons, F. G., and Kofsky, I. L., Nature 203, 1196 (1964).

[4] Kuttner, P., Appl. Optics 7, 1029 (1968).

[5] American Standard PH 2.1 (American National Standards Institute, New York, 1952).

[6] Jones, R. A., and Coughlin, J. F., Appl. Opt. 5, 1411 (1966).

[7] Galburt, D., Jones, R. A., and Bossung, J. W., Photo. Sci. Eng. 13, 205 (1969).

[8] Charman, W. N., Appl. Optics 4, 289 (1965).

[9] Linfoot, E. H., Fourier Methods of Optical Image Evaluation, Chapt. III, (Focal Press, London, 1964).

[10] Duecker, H. C., and Lippincott, E. R., Rev. Sci. Instr. 35, 1108 (1964).

[11] Benedetti, P. A., and Viola-Magni, M. P., J. Sci. Instr. 43, 141 (1966).

[12] Arndt, U. W., Leigh, J. B., Mallett, J. F. W., and Twinn, K. E., J. Sci. Instr. 2 (Ser. 2), 385 (1969)

[13] Rohner, E., and Strutt, M. J. O., Rev. Sci. Instr. 28, 1074 (1957).

[14] Simonds, J., The Sensitometry of Color Films and Papers, Chapt. 21 in The Theory of the Photographic Process, eds. C. E. K. Mees and T. H. James (MacMillan Co., New York, 1966).

[15] Powers, S. A., and Miller, D. E., Photo. Sci. Eng. 7, 59 (1963).

[16] Williams, R. O., Monograph, The Cincinnati Milling Machine Co., from talk at Cincinnati Technical Activities Seminar (1957).

[17] Perrin, F. H., The Structure of the Developed Image, Chapt. 23 in The Theory of the Photographic Process, eds. C. E. K. Mees and T. H. James (MacMillan Co., New York, 1966).

[18] Abbott, F., Opt. Spectra 64 (April 1970).

[19] Jones, R. A., Photo. Sci. Eng. 11, 102 (1967).

(Paper 75Cl-310) 